\title{
Does Visual Training Provide Competitive Advantage in the Perceived Stressful Situations of a Tennis Match?
}

\author{
Federico Di Carlo \\ Atri, 64030 (Te), Italy
}

\begin{abstract}
Vision training is often proposed through the unchallenged assumption that the training of sight skills is paramount to vision and can improve competitive performance. A growing body of neuroscientific literature demonstrates that most vision processes happen as a result of inside-out rather than outside-in neural pathways. Training systems and methods are often being counselled, promoted, and accepted as solve-it-all approaches without statistic and scientific evidence that training improvement can be transferred from training sessions to competitive performance.
\end{abstract}

Key words: Vision, sight, visual training, neuroscience, scientific evidence.

\section{Introduction}

Training methodologies change in time and tennis does not make an exception. New technologies applied to research and sport allow athletes to exceed current performance standards and levels. Sometimes, however, training technologies are being proposed, offered and accepted as performance enhancers breakthroughs without being challenged and proved beyond doubts by statistic evidence. The above is an excursus through neuroscientific and other research fields whether visual training in tennis meets the above requirements.

Anyone involved in tennis understands, even at an intuitive level, that sight is indeed extremely important in our sport. The sense of sight is indeed paramount to human cognition and the combined processes of sight and vision involve at least $60 \%$ of cognitive resources [1]. Most research in the field of cognitive studies focused on the role of sight in stimuli acquisition [2, 3]. However, the effects that the athlete's mental state may have on visive stimuli acquisition is just now being studied and taken into consideration [4]. In fact, most tennis motor responses in competition are reflexive and

Corresponding author: Federico Di Carlo, B.A., research field: languages and humanistic sciences. automated, mostly depending on muscle motor memory [5-7].

Following the cognitivist tendency of considering the brain as the central factor in human behavior, the input sense systems which are located closer to the brain (vision and hearing) have always attracted the attention of researchers. The tendency is kept in tennis literature as well and tennis players are considered as if they were robots instead of human beings. It is rather questionable whether lateralized sight strategies during competitive performance may benefit player performance.

\section{Literature Review}

As early as 1922, Bill Tilden stated that among the many causes for missing strokes, one of the most important is that player does not look at the ball at the time of hitting it. About $80 \%$ of mistakes in tennis, according to Tilden are due to taking the eye from the ball in the last one fifth of the ball flight. Tilden was also the one to start the metaphor of the eyes as a camera and the impossibility to keep clear both the subject and the background of a moving object. The same happens in the relationships between the ball and the environment (opponent, court and so on). Bill Tilden was urging that tennis players kept their eyes on 
the ball and that by keeping the eyes on the ball complete flight the player may have the chance to reduce errors by five times [8].

The interest in the sight aspect of training had a climax in the eighties when researchers studied the processes of sight in sport by making applied research and technological experiments on the field with athletes. Stein and Slatt [9] demonstrated that at the moment of contacting the ball at high speed the player can see just a blur. Actually the findings of Stein and Slatt were not taken into serious consideration until Vic Braden acknowledged the fact that when the ball travels at more than forty-five $\mathrm{km} / \mathrm{hr}$ (much less than a normal ball speed in professional tennis) about one and a half meters from a player which is chasing the ball (moving), the ball enters into a fog zone and the eye sees the ball as a blur. In fact, the sight of such a moving object corresponds to legal blindness [5].

Over the years, the studies by Bahill and Laritz [10], Haywood [11], Ripoll and Fleurance [12] have endorsed the point that seeing the ball complete flight is not physically possible and not technically advisable for the athlete. In the twenty first century, several other researchers have devised alternative sport "visual" techniques-Mac Leod [13], Lafont [14-17], Vickers [18], Albernethy [19] which re-confirm the eye physical limits and stress out the necessity to focus on a sound cognitive vision strategy rather than sight skills.

\section{Methodology}

Neuroscientific studies indicated that two types of mechanisms are used in visual perception: "bottom-up" mechanisms are driven by the input from the eyes [20] in contrast, "top-down" mechanisms make use of stored information (such as knowledge, belief, expectations, and goals) [21, 22]. There is a growing body of neuroscientific literature which indicates that in most cases the player mental state is paramount to player visual strategy. The studies on inattentional blindness [23] demonstrate that whatsoever the sight skills, human cognitive processes have strong limitations.

Moreover, neuroscientific studies carried out by functional magnetic resonance (fMRI), electroencephalogram (EEG) and positron emission tomography (PET) indicate that most vision processes happen as a result of inside-out rather than outside-in neural pathways [24]. The primitive instinct for survival and the paramount role of memories determine that under perceived stressful situations the human beings experience and react to stimuli in an emotional aroused rather than calm ways in most cases [25]. Neural pathways under stressful situations as they may be perceived in a tennis match will tend to instinctive and/or primordial activation and/or more consolidated neuro conditioning [26]. The activation of the Old Mammalian and Reptilian neural patterns impairs vision and perceptions [27]. The Reptilian in particular is the part of our brain which controls instincts and basic needs such as self-defence, reproduction, and digestion. There are located centers that control the autonomic nervous system. This is especially important, of course, because the focusing of the eye is mostly an automatic function.

The very intense emotion of frightening may cause paralysis, the pupils dilate, and the eyelids retract. When the eye muscles freeze, saccadic eye movements are diminished and the image is not seen clearly. In the visual system when the eyes freeze, the eyelids retract, and the perceptual field shrinks [28]. When choking reaches its climax, the tennis player enters a mental state of "dis-association" where body and mind are no longer integrated. The athlete is in the court but he is no longer present in what he is doing [29]. It depends on the athlete history, situation, and case how the fear response mechanism may impair the athlete performance. On above situations poor eyesight is due to mental strain. Mental strain is caused by stress. Stress is a form of fear. The response to fear is automatic and out of conscious control [30]. When the strain is temporary (as in the case of champions, experts, purposefully trained, low level neurotics, and 


\section{Stressful Situations of a Tennis Match?}

so on), the system returns to its normal strain-free state. The eyes stop staring, pupils return to an appropriate size, muscles relax, heart rate decelerates, and breathing normalizes [30].

Most sport "visual" trainers assume that the process of vision happens only by thought process, evoke-response, or through trained response. However, the process of vision under fear mechanism stimuli response is just a survival, instinctive, reactive, and reflex response [31]. If the athlete trains the sight strategy (effect) and not the mental state that causes it (cause), any time that the situation (stimulus) triggers the cause, the behaviour will tend to be consistent with the mental state and not with the sight strategy. Mind-states cause sight strategies more than being an effect of sight strategies [32].

Sight and vision are often confused and mixed in a single visual training approach as if they were synonyms. In fact, they are not and have completely different nature and processes. Sight is the ability of the eye to resolve detail and to see clearly, a process that brings outside stimuli inside the cognitive processes [2]. Vision is the anticipation, reconstruction, and interpretation of what is seen, a process which is defined inside-out, that is: the physiologic and mental process determine the perception feedback and response to the outside stimulus [3]. While in the first case, seeing is rather an objective process, in the second case, it is mainly considered as a subjective experience.

If sight strategy is paramount to a player's performance, the questions to be answered are of different nature. It has been written that sight strategy has a profound impact on concentration, control, flow, the zone, stress and anxiety, staying in the present [33]. If the assumption is correct, how come that one tennis player can perform a visual strategy on one stroke and a different one within the other stroke within the same rally? How come that even elite players may have a visual strategy for one shot in one situation and a completely different one for the same stroke in a different play situation within the same match? How come that the visual strategy of even the best conditioned, trained, and performing tennis players can be so different according to strokes and situations?

By comparing the pictures below, you may notice that the head and the visual strategies adopted by the same player are quite different. Comparing the Sharapova images (Figs. 1 and 2), Fig. 2 shows that not only the gaze is in front and not on the contact point (Fig. 1) but that all

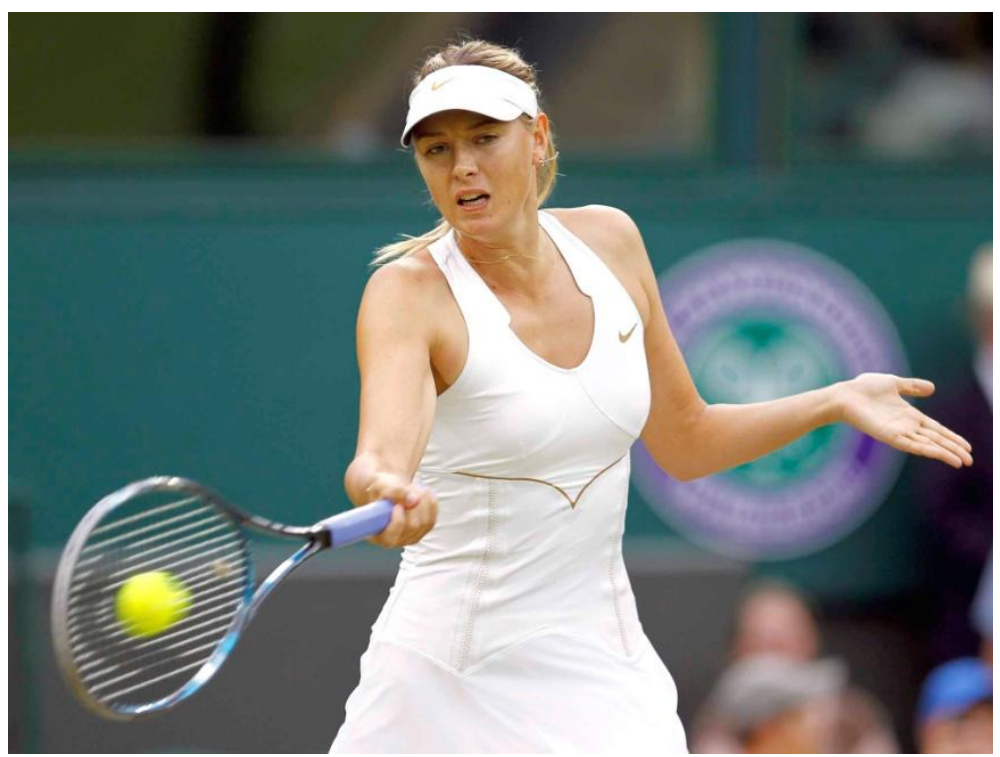

Fig. 1 Maria Sharapova performing a forehand stroke. 


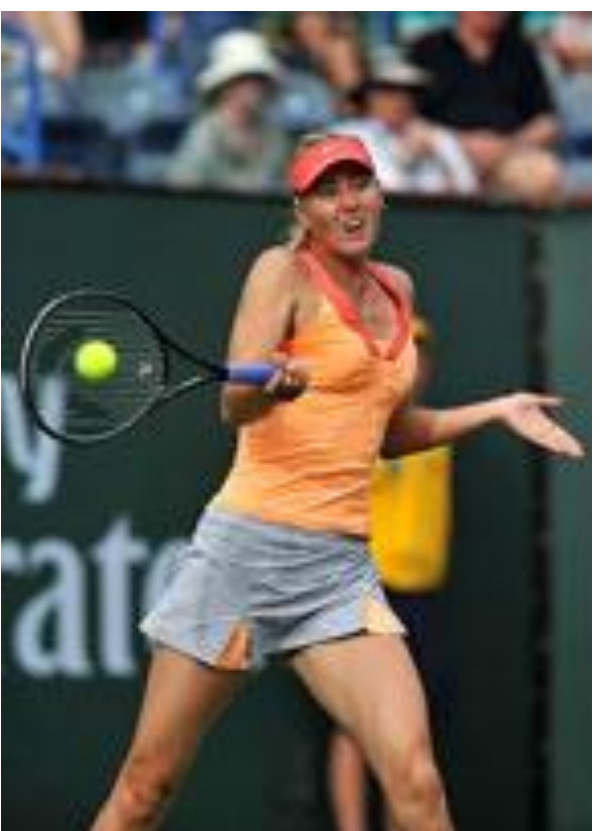

Fig. 2 Maria Sharapova performing a forehand stroke.

body language is different. Same shot (forehand) but executed in a completely different mind-set (different situations). The images by Serena Williams (Figs. 3 and 4) are even more explicatory. While executing a forehand shot, her head and eyes are exactly on the contact point (Fig. 3). She is nose breathing, her face is relaxed as much the body. In the backhand side (Fig. 4), head and eyes are facing the opponent, she is breathing by mouth and face and body are extremely tensed.
Federer himself, by all students credited as being the master at head-eye fixation at contact, when in perceived stressful situation, though keeping eye fixation technique, often frame hit the balls on his back hand side. If the mental state is one of cognitive or emotional nervousness, doubt, anxiety or fear, the outside stimulus will be perceived as a dangerous one and gradually limiting the cortex work and increasing the interference of the mid brain [34].

The answers to the questions above stated are not to be found in standardized sight perceptive strategies. The players biomechanical analysis, as showed in the pictures above, indicates that players sight and vision strategies are adaptive. "Visual" theories applied to tennis so far rely on the assumption that eyes see and brain reacts as if seeing was a eyes perceptive process only and images processed by eyes were perfect and vision occurred in the cortical region of the brain only [35].

\section{Discussion}

\subsection{Methodological Implications}

There is plenty of evidence that visual training improves vision skills in sports practice and tennis is not an exception [36]. However, while advising visual

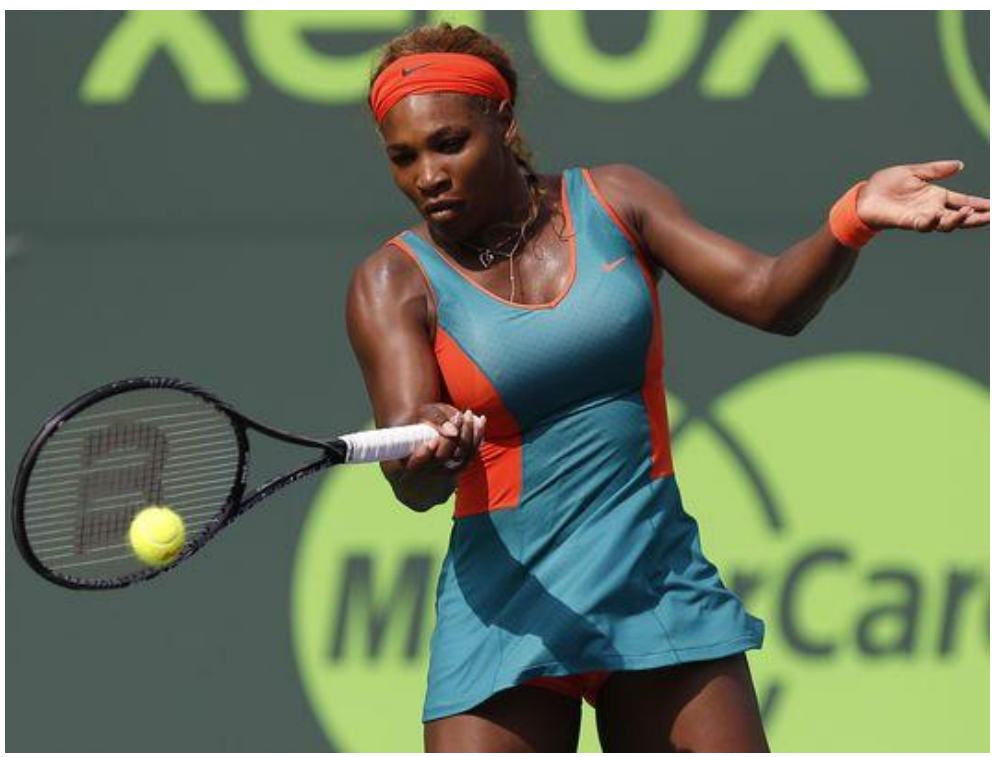

Fig. 3 Serena Williams performing a forehand stroke. 


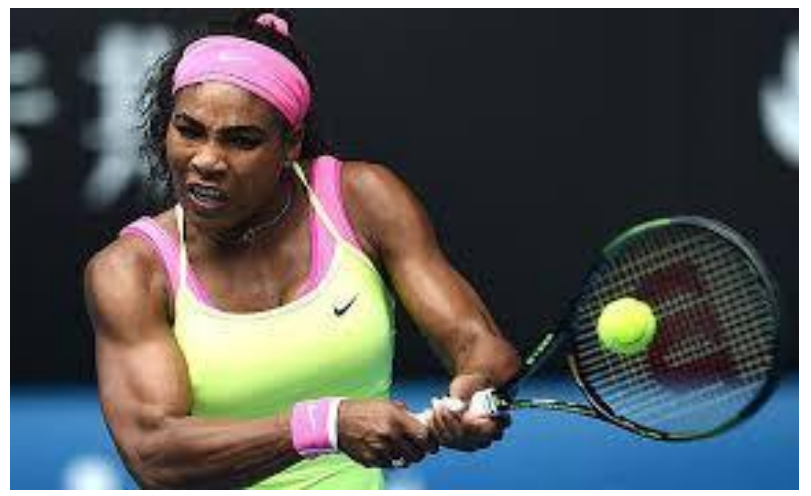

Fig. 4 Serena Williams performing a backhand stroke.

training, it should also be mentioned that: (1) Generic vision training produces any or negligible sport vision skill improvement. Vision training to be effective in practice needs to be sport specific [37]. (2) Reversibility is one of the basic assumptions of training $[38,39]$. It is predicted that if visual training regime is not kept specific and consistent in time there should be a recession/downgrade of the eyes organs and visual trained skills. There is no literature to my understanding that included reversibility in the study of sports visual training. (3) There is no statistical evidence whatsoever that above vision improved skills in practice are transferred and being consistently and successfully applied by players during stressful critical moments of official competitive performance.

\subsection{Effects of Visual Training on Competitive Performance}

Whenever considering the effects of visual training on performance it should also be reminded that: (1) Most elite athletes have above-average sight skills due to many factors as genetics, environment, and specific sport practice to name a few. A statistic research in US among young population in the age between nineteen and thirty-four showed that $59 \%$ of the population have some form of sight deficiency. The same research made among NFL, NBA, NHL, MBL players show that on average just $24 \%$ of the athletes have sight deficiencies [40]. (2) There is no consistent evidence that "vision" training improves match competitive performance. Most literature evidence provided is based on sports practice and personal accounts of successful players that were submitted to some visual training practices or exercises [38]. fMRI, EEG, PET and other biometrical technologies are too invasive, can not be used and are not allowed to analyse the player performance in competition. Therefore, there is no research, no tangible and statistical evidence which definitively proves beyond doubts that above players were able to apply those skills constantly and successfully in official match play under high competitive pressure or critical moments. There are studies that offer a sceptic position about vision training and suggest that the benefits of visual training consist in a placebo effect and confidence boosting [41, 42]. More conscientious visual trainers admit that: "There are many variables (diet, peaking, visualizing, conditioning etc.) that make it difficult to prove beyond doubt either that improved results on sports vision equipment in the laboratory or consulting room are transferable to the sporting arena or that improvements in sporting performance are due, even in part, to sports vision training [28]." (3) Most tennis players respond better to kinaesthetic and acoustic inputs rather than visive ones [32]. In a personal unpublished research I carried out on 100 elite players, $67 \%$ were kinaesthetic, $24 \%$ auditive and just $9 \%$ visive. Tennis practice and methodology cannot be a stock program. It must be personalised and custom made. (4) Sight and vision are two different issues. Tennis players that have problems with static acuity, dynamic visual acuity, depth perception, peripheral awareness, eye-hand coordination, should consult an optometrist. Whether competitive performance is not up to practice performance visual training might be just one of the multiple aspects to address [43]. (5) There are no panacea methods, no short cuts to hard work and personal responsibility cannot be skipped. Many sales proposals rely on the athlete sense of blame. Advertisement purpose is to explain the athlete failure since he/she hasn't tried such and such methods or products so far while other athletes have and were 
successful. It is manipulation through emotional blackmail. Human beings are prone to skip responsibility and to trust on external aid. Proposals will be backed by research evidence. There is as much research evidence which claims the exact way round. The morale is: people have in themselves most of the skills and resources required to succeed. There is no short cut to hard work and self-determination. (6) New methods and new technology training aids are welcome to make tennis practice more stimulating, fun, and enjoyable but there is no substitute for basic training. There is plenty of new teaching methodology and amenities which stress out and enhance visual, auditory, and kinaesthetic stimuli. However, there is no better practice which fakes, reproduces, and resembles real sport situation, which is: chasing and hitting a ball [28].

\section{Conclusions}

New technologies, training methodologies, and approaches are welcome in sport but they should be personalised and player customised. More important, whatever the approach, it should be proved by statistic evidence. Moreover, whatever the tennis performance, it should be at least evaluated within the overall training regime. No single training practice alone transforms into performance enhancer. Gaze data and visual training may be useful in providing tennis players cues for optimal attentional control but it is no panacea. Athletes are individuals who are more than image-processing machines.

\section{References}

[1] Schmidt, R. A., and Wrisberg, C. A. 2007. Motor Learning and Performance. Champaign, IL: Human Kinetics.

[2] Gibson, J. J. 1966. The Senses Considered as Perceptual Systems. Boston: Houghton Mifflin.

[3] Gregory, R. 1974. Concepts and Mechanisms of Perception. London: Duckworth.

[4] Bekkering, H., and Neggers, S. F. 2002. "Visual Search Is Modulated by Action Intentions." Psychological Science 13 (4): 370-4.

[5] Braden, V., and Wool, R. 1993. Mental Tennis. How to Psych Yourself to a Winning Game. NY: Little Brown and
Company.

[6] Weinberg, R. 2002. Tennis, Winning the Mental Game. Oxford, Ohio: Miami University.

[7] Spang, P. 1998. Zennis. New York: The Berkley Publishing Group.

[8] Tilden, B. 1922. The Art of Lawn Tennis. Second Edition. 36 Essex Street W.C., London: Methuen \& Co ltd.

[9] Stein, H., and Slatt, B. 1981. Hitting Blind. The New Visual Approach to Winning Tennis. NY: Beaufort.

[10] Bahill, A. T., and LaRitz, T. 1984. "Why Can't Batters Keep Their Eyes on the Ball?" American Scientist 72: 249-3.

[11] Haywood, K. M. 1984. "Use of Image-Retina and Eye-Head Movement Visual Systems during Coincident Anticipation Performance."Journal of Sports Sciences 2 (2): 139-44.

[12] Ripoll, H., and Fleurance, P. 1988. "What Does Keeping One's Eye on the Ball Mean?" Ergonomics 31 (11): 1647-54.

[13] Land, M. F., and McLeod, P. 2000. "From Eye Movement to Actions: How Batsmen Hit the Ball." Nature Neuroscience 3: 1340-5.

[14] Lafont, D. 2007. "High-Speed Photo Analysis of Top Players' Gaze Behavior." in Tennis Science and Technology, edited by Miller, S., and Capel-Davies, J. London: ITF, 227-33.

[15] Lafont, D. 2007. "Watch the Ball?" ITF Coaching and Sport Science Review 43: 11-2.

[16] Lafont, D. 2007c. "Six Good Reasons to Keep Your Eye off the Ball." ITF Coaching and Sport Science Review 44: 5-6.

[17] Lafont, D. 2007. "Toward a New Hitting Model in Tennis." International Journal of Performance Analysis in Sport 7 (3): 106-16.

[18] Vickers, J. N., and Adolphe, R. A. 1997. "Gaze Behavior during a Ball Tracking and Aiming Skill.” International Journal of Sport Vision 4 (1): 18-27.

[19] Mann, D., Spratford, W., and Abernethy, B. 2013. "The Head Tracks and Gaze Predicts: How the Best Batters Hit a Ball." PLoS ONE 8 (3): e58289.

[20] Gregory, R. 1970. The Intelligent Eye. London: Weidenfeld and Nicolson.

[21] Cerminara, N., Apps R., and Marple-Horvat, D. 2009. “An Internal Model of a Moving Visual Target in the Lateral Cerebellum.” J. Physiol. 587 (2): 429-42.

[22] Moreau, D. 2013. "Motor Expertise Modulates Movement Processing in Working Memory." Acta Psychologica 142 (3): 356-61.

[23] Menmert, D. 2006. "The Effects of Eye Movements, Age and Expertise on Inattentional Blindness." Consciousness and Cognition 15 (3): 620-7.

[24] Weisenger, H., and Pawliw-Fry, J. P. 2015. Performing 


\section{Stressful Situations of a Tennis Match?}

under Pressure. The Science of Doing Your Best When It Matters Most. NY: Crown Business.

[25] Robertson, I. 2000. Mind Sculpture. Unleashing your Brain's Potential. London: Bentam Books.

[26] Fox, A. 2010. Winning the Mental Match. Kearney, NE, US: Morris Publishing.

[27] Duncan, S., and Barret, L. F. 2007. "The Role of the Amygdala in Visual Awareness." Trends in Cognitive Sciences 11 (5): 190-2.

[28] Loran, D. F. C., and MacEwen, C. J. 1997. Sports Vision. Oxford: Butterworth-Heinemann.

[29] Jackie, R. J., and Dekkers, H. 2007. Mindset. Amsterdam: Mindset Publishers.

[30] Murray, J. 1999. Smart Tennis: How to Play and Win the Mental Game. San Francisco: Jossey Bass.

[31] Belcetis, E., and Dunning, B. 2006. "See What You Want to See: Motivational Influences on Visual Perception." Journal of Personality and Social Psychology 91 (4): 612-25.

[32] Di Carlo, F. 2015. "Neuroscientific Approach to Vision Training in Tennis." Conference on the Mental Aspects of Tennis, Teramo, Italy.

[33] Ford, S. 2014. Welcome to the Zone. Outskirt Press, Inc.

[34] Beilock, S. 2010. Choke. What the Secrets of the Brain Reveal about Getting It Right When You Have to. NY: Free Press.

[35] Gibson, J. J. 1972. "A Theory of Direct Visual Perception.” In The Psychology of Knowing, edited by Royce, J., and
Rozenboom, W. New York: Gordon \& Breach.

[36] Maman, P., Gaurang, S., and Sandhu J. S. 2011. "The Effect of Vision Training on Performance in Tennis Players.” Serbian Journal of Sports Sciences 5 (1): 11-6.

[37] Abernethy, B., and Wood, J. M. 2001. "Do Generalized Visual Training Programs for Sport really Work? An Experimental Investigation." Journal of Sports and Sciences 19 (3): 203-22.

[38] Mujika, I., and Padilla, S. 2000. "Detraining: Loss of Training-Induced Physiological and Performance Adaptations. Part 1: Short Term insufficient Training Stimulus." Sports Med. 30 (2): 79-87.

[39] Mujika, I., and Pacilla, S. 2000. "Detraining: Loss of Training-Induced Physiological and Performance Adaptations. Part II: Long Term Insufficient Training Stimulus." Sports Med. 30 (3): 145-54.

[40] Peters, M. A. 2012. See to Play. Minneapolis: Bascom Hill Publishing Group.

[41] Cockerill, I. M., and McGillivary, W. W., eds. 1981. Vision and Sport. W. Celthenam: Stanley Thornes.

[42] Napel, J. 1993. "Can Visual Training Improve Athletic Performance?" In Transaction of the First Symposium of the Sports Vision Association, London, UK: The City University.

[43] Di Carlo, F. 2012. The Tennis Brain. Vasto, Italy: \&Mybook. 1-334. (in Italian) 